\title{
A SIMPLE METHOD FOR THE EXTENSION OF SHELF LIFE OF CULTURES OF PHYTOPHTHORA SPECIES CAUSING BLACK POD DISEASE OF CACAO (THEOBROMA CACAO L.)
}

\author{
I. Amoako-Attah*, E. Kumi-Asare And Y. Bukari \\ (Plant Pathology Division, Cocoa Research Institute of Ghana). \\ *Corresponding author's email: amoakosi@yahoo.com
}

\begin{abstract}
Black pod disease of cacao caused by Phytophthora palmivora and Phytophthora megakarya in Ghana take heavy toll of cacao production in the field. Intensive research has been carried out worldwide on these pathogens. However, viability of the cultures during prolonged storage has remained a major challenge in the research. This paper reports findings of assessment of six storage media viz sterilised distilled water (SDW), sterilised and unsterilized soil suspension (SSS and USS), vegetable 8 juice broth (V8JB), Oat Meal Agar slant under mineral oil (at $\left.4{ }^{\circ} \mathrm{C}\right)$ and empty tube. Viability of the cultures was assessed on V8JA and in tetrazolium chloride test. Ability of zoospores of the cultures to infect cacao leaf discs was used to assess growth vigour and pathogenicity. Phytophthora cultures stored in SDW (26 \pm $2{ }^{\circ} \mathrm{C}$; alternating day light and night) were preserved for 60 days (5 years). Both P. palmivora and $P$. megakarya performed better on SDW and SSS than on USS due to removal of staling substances in the soil medium by the sterilisation. Vigour of growth and pathogenicity of the stored cultures required re-inoculation of host tissue (cacao pod) in order to maintain potency to continually infect host.
\end{abstract}

Keywords: Phytophthora cultures, pod rot, soil water, sterilised and unsterilised, survival, virulence

\section{Introduction}

Theobroma cacao L. (cacao) is a major cash crop in Ghana and the main raw material for the chocolate industry. One of the most important diseases affecting the crop worldwide is known as Phytophthora pod rot (commonly called black pod disease). There are at least four economically important Phytophthora species (P. megakarya, P. palmivora, P. citrophthora and $P$. tropicalis/capsici) causing the disease on cacao (Surujdeo-Maharaj et al., 2016). In Ghana, cacao pod rot disease is caused by $P$. megakarya and P. palmivora. Pod losses up to 100\% have been reported (Dakwa, 1988). As a result, priority research work is conducted annually on these species (Bailey et al., 2016). Some of the research are to better understand the biology, genetic diversity, population dynamics, adaptation and host-pathogen interrelationships for efficient management of the cacao disease. Preserving Phytophthora species in culture for a long period to maintain genetic and morphological stability has been problematic. The conventional way of preserving fungal culture has been to keep it on agar slant. This requires frequent transfer onto fresh agar medium. Continuous sub-culturing over a period of time leads to reduction in 
pathogenicity, virulence and growth rate of isolate (Losch et al., 2010; Ansari et al., 2011). Maintaining an isolate on a host tissue is probably the best way to preserve the pathogenicity as reported for $P$. infestans (Świszczewska et al., 1971). However, the necessary standard procedure of re-inoculation of isolate to fresh tissue is very laborious and time consuming. In some instances, preserving a culture on silica gel, in soil or sand is useful but there is still the risk of serial transfers with the accompanying loss of some morphological characters and pathogenicity (Windels et al., 1993; Granke et al., 2012). Other methods of preserving Phytophthora species are based on slowing down fungal metabolism at low temperature and under limited oxygen access. Cultures in our laboratory are maintained as such, under mineral oil at $4^{\circ} \mathrm{C}$, for a maximum period of six months. The increasing number of Phytophthora collections requires large amount of space and work on sub-culturing the cultures continuously at regular intervals. Lyophilization and liquid nitrogen storage ensure long-term viability of most large collections worldwide with distinct advantages of saving labour cost and preserving the fungus in its original genetic state (Ryan et al., 2000; Sobkowiak et al., 2012). However, the method requires special equipment and it is expensive and capital intensive to maintain.

Phytophthora species have been maintained in sterilised distilled water (SDW) successfully for a long period. Ko (2003) reported that cultures of $P$. parasitica, $P$. palmivora and $P$. cinnamomi were viable in SDW at room temperature $\left(25^{\circ} \mathrm{C}-26^{\circ} \mathrm{C}\right)$ for six to 23 years. This simple and inexpensive method was also used to preserve $P$. cactorum and $P$. megasperma var sojae for 3-8 years at room temperature (Sutton et al., 2007). In spite of these successes, some species of
Phytophthora including $P$. parasitica which were kept at $5^{\circ} \mathrm{C}$ survived only one year in water while isolates of $P$. infestans and $P$. colocasia survived only 2 - 6 months (Marx \& Daniel 1976). This implies that low temperature is not suitable for water storage of Phytophthora. In the present study, the suitability of six different storage media for long-term preservation of Phytophthora palmivora and $P$. megakarya were assessed at room temperature $\left(26 \pm 2^{\circ} \mathrm{C}\right)$. The fungal resistant resting organ responsible for long-term survival and maintenance of morphological and pathological stability of the Phytophthora species were studied and described.

\section{Experimental}

\section{Fungal isolates}

Five isolates of each species of $P$. palmivora and $P$. megakarya from collections at Cocoa Research Institute of Ghana were used. The pathogens were originally isolated from cacao pods showing black pod disease symptoms and maintained on oatmeal agar (OMA) slants in a cold room $\left(4^{\circ} \mathrm{C}\right)$. The isolates were resuscitated by sub-culturing on $20 \%$ clarified V8 juice agar (V8JA) plates containing antimicrobial amendments pimaricin, ampicillin, rifampicin, pentachloronitrobenzene (PARP) (Ferguson \& Jeffers, 1999). They were subsequently inoculated twice, successively, to cacao pod (Mocorongo clonal variety). The re-isolated fungal pathogens were cultured on Oxoid corn meal agar (CMA) prepared according to manufacturer instructions. They were allowed to grow vegetatively under total darkness at $25^{\circ} \mathrm{C}$ for 7 days and subsequently transferred into continuous light (1,400 lux, SunLite, China) for 3 days to induce sporulation before use. 


\section{Storage methods}

Six storage media: sterilised distilled water (SDW), sterilised and unsterilized soil suspension (SSS and USS), vegetable 8 juice broth (V8JB), OMA slant and empty (unfilled) glass tube at room temperature were evaluated. In the SDW medium, a clear glass tube $(25$ $\mathrm{mm}$ diam $\times 82 \mathrm{~mm}$ long) containing $10 \mathrm{~mL}$ distilled water was sterilized by autoclaving at $121^{\circ} \mathrm{C}$ for 15 minutes. Mycelial agar plugs (5$\mathrm{mm}$ ) were aseptically taken from the margins of 10 day-old pure culture of Phytophthora isolate growing on CMA into the tube and capped tightly. For soil suspensions, $15 \mathrm{~g}$ of sieved (2 mm mesh) soil from uncultivated field was added to 1 liter distilled water and stirred overnight with magnetic stirrer (Fisher Scientific, Penn USA). The soil particles were allowed to settle out of suspension after 5-h and $10 \mathrm{~mL}$ of aqueous portion transferred to glass tubes. The tubes were either sterilised at $121^{\circ} \mathrm{C}$ and $1.1 \mathrm{~kg} / \mathrm{cm}^{3}$ pressure for 15 minutes or unsterilised and used to store mycelial plugs as sterilised soil suspension (SSS) or unsterilised soil suspension (USS). Mycelial plugs were aseptically transferred into 10 $\mathrm{mL}$ of $\mathrm{V} 8 \mathrm{JB}$ tube containing $10 \%$ clarified V8 juice (Campbell USA) and $0.02 \% \mathrm{CaCO}_{3}$ (Ferguson \& Jeffers 1999). Similar transfers were made into empty tube and OMA slant. The OMA slant contained $10 \mathrm{~mL}$ filtrate from $4 \%$ oat flakes soaked overnight and $2 \%$ agar. The plugs were allowed to grow on the slant as previously for 10 days. Sterile mineral oil (Sigma, molecular biology grade) was added to the tube until fungal colony was completely covered. The slant was kept in an upright position and the oil level checked monthly. In all the tests, ten 5-mm diameter mycelial plugs were placed into each tube and 20 replicate tubes (4 tubes/isolate) kept for each storage medium per species. All the tubes were sealed with Parafilm (Bemis flexible packaging, Neenah, Wisconsin) prior to storage in the dark at room temperature $\left(26 \pm 2^{\circ} \mathrm{C}\right.$; alternating day light and night). Plugs on OMA slants were stored at $4{ }^{\circ} \mathrm{C}$ in the dark for comparison. The viability and morphological characteristics of fungus from each storage treatment at 3 months intervals were assessed for 18 months and subsequently once a year up to five years. Prior to storage of these cultures, the mycelial growth rates of the test isolates were determined on VJ8A plates and disease lesion sizes on cacao pods (Mocorongo clonal variety) recorded. This was to ensure that the cultures were viable and have their pathogenicity intact. The data was also used subsequently to ascertain loss or increase in the vigour of growth of the cultures after storage.

\section{Viability test}

To test for viability of the stored cultures, five replicate tubes (per isolate) from each treatment were selected, then one plug from each tube was blotted-dry on tissue paper and placed on a fresh V8JA medium. A mycelium colony forming from each treatment on V8JA at $25^{\circ} \mathrm{C}$ was considered as viable. Where there was no colony growth from the treatment, it was considered as non-viable. In a nonviability response, the test was repeated for the remaining mycelial plugs until all tubes were exhausted for a treatment.

\section{Detached pod test}

Mocorongo cacao genotype was selected for this work because of its known susceptibility to Phytophthora pod rot disease (Nyadanu et al., 2009). Five hand-pollinated-trees were chosen and forty (40) healthy pods were harvested four months after pollination. The pods were surface sterilised by immersion in $10 \%(\mathrm{v} / \mathrm{v})$ commercial bleach (Clorox, Ghana) for a minute and then rinsed twice in SDW. A 7-mm diameter and 6-mm deep wounds were 
made on the pods and test fungal plugs from each storage medium placed in the wounds and covered with the excised tissues. The pods were arranged in a completely randomized design with five replications inside an aluminum tray $(72 \times 62 \times 10 \mathrm{~cm})$ lined with moist plastic foam (Latex Foam, Ghana Ltd). Beakers of SDW were placed inside the trays, covered and sealed to maintain humidity at $80-100 \%$ ERH. The trays were kept under laboratory conditions $\left(26 \pm 2^{\circ} \mathrm{C}\right.$; alternating day light and night regimes) and examined after 7 days for infection and re-isolation of the test fungus. The mycelial plugs causing Phytophthora pod rot lesion were scored as virulent. The disease lesion sizes on the pods were traced on transparent paper and assessed from brown-paper cut-outs trimmed to the size of each lesion. The area of paper cut-outs was determined with a leaf area meter (WinDIAS, Delta-T device Ltd, Cam, England).

To assess the vigour of growth (aggressiveness) of the fungal cultures after storage, the five isolates of each species of Phytophthora used for the storage experiment were initially inoculated to Mocorongo cacao pods as described above. Sizes of the disease lesions recorded from the pods after 7 days served as baseline data (initial lesions) of the cultures before storage. During the study, disease lesion sizes of the cultures were compared as a ratio of the initial lesion size (before storage) to the lesion size after fungal storage. Lesion ratios less than 1 indicated loss of fungal aggressiveness.

\section{Tetrazolium chloride test}

The standard tetrazolium chloride test was employed to study morphological structures of the chlamydospores and the viability of the attendant mycelial mat formed. Mycelial mats were teased out from the stored plug of the medium onto a glass microscope slide. The mycelium was soaked in 1-2 droplets of freshly prepared $1 \%$ tetrazolium chloride solution (2,3,5-triphenyl tetrazolium chloride, TTC). The culture mats were incubated at 26 $\pm 2{ }^{\circ} \mathrm{C}$ in the TTC solution on the slide for $4 \mathrm{~h}$. Viable Phytophthora cultures stained pink (or violet) after incubation while non-viable ones remained hyaline (clear). Chlamydospores also stained pink while non-viable ones remained black after incubation. The stained fungal tissues were observed and photographed under a Nikon Eclipse E600 fluorescent microscope (Nikon, Inc., 1300 Walt Whitman Road, Melville, NY, USA) mounted with Nikon Digital Camera (DXM1200).

Zoospore inoculum, estimation of population of P. palmivora or P. megakarya

Zoospore production by the zoosporangia of $P$. palmivora and $P$. megakarya was assessed by first incubating the cultures from each storage treatment growing on fresh V8JA plates at $25^{\circ} \mathrm{C}$ in the dark and then under continuous light for a total of 10 days as previously described. Thereafter, each plate $(9 \mathrm{~cm}$ diameter) was flooded with $10 \mathrm{~mL}$ chilled SDW $\left(4^{\circ} \mathrm{C}\right)$ and kept in a refrigerator $\left(4^{\circ} \mathrm{C}\right)$ for 45 minutes to induce zoospore release (discharge). The plates were transferred into total darkness in an incubator $\left(28^{\circ} \mathrm{C}\right)$ for 30 minutes. The discharged zoospores were immobilized by adding 1-2 drops of 70\% ethanol. Exactly, 1 $\mathrm{ml}$ suspension of immobilized zoospores was used for counting under light microscope (Leica) at low (x 10) magnification using haemocytometer (KOVA International Inc., USA). The total number of zoospores after five (5) repeated counts was calculated as: (average number of zoospores) $\times 10^{4}$. For the leaf disc preparation and inoculation test, healthy leaves of 3-months old cacao seedlings of Mocorongo clones were hand-washed under running tapwater. The leaves were then rinsed twice in 
SDW and wiped-dry with tissue paper. A cork borer $(1.5 \varnothing)$ was used in cutting the leaf discs. The leaf discs were inoculated at the center on the abaxial surface with $10 \mu 1$ zoospore suspension (approximately $20 \times 10^{4}$ zoospore/ $\mathrm{ml}$ ) of either $P$. palmivora or $P$. megakarya. The leaf discs carrying the $P$. palmivora and $P$. megakarya were arranged using a completely randomised block design and then incubated inside aluminum tray as previously described. The leaf discs were scored at 6 days after inoculation at $25^{\circ} \mathrm{C}$ for infection using a five point hedonic scale described by Nyassé et al. (1995). This is represented in Fig. 1:

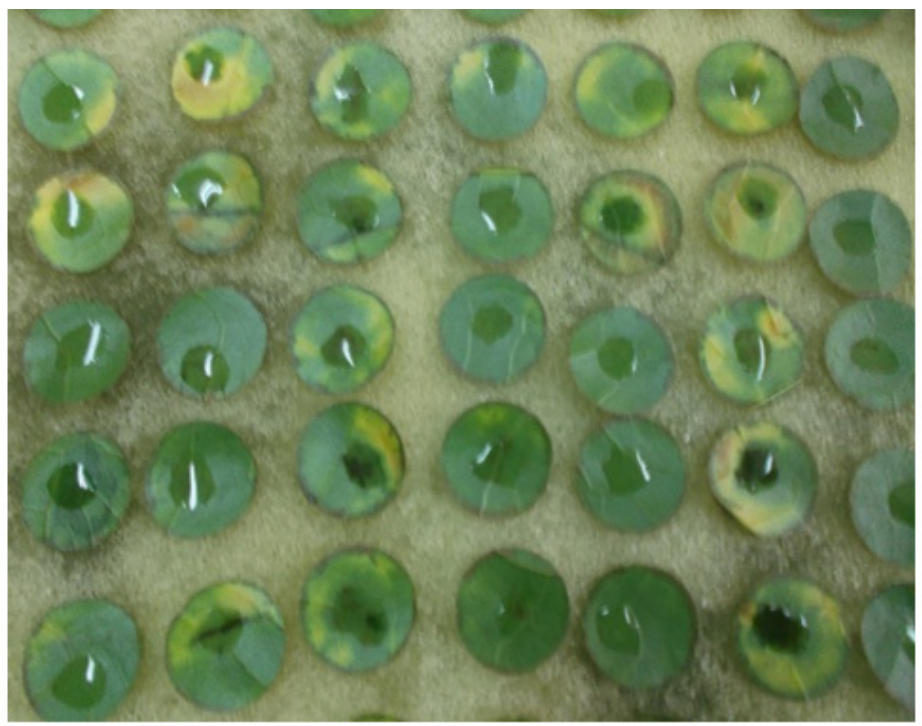

\begin{tabular}{|l|l|c|}
\hline Symptoms on leaf disc & Symtom description & $\begin{array}{l}\text { Assessment } \\
\text { scale }\end{array}$ \\
\hline & No symptoms & 0 \\
\hline & Very small necrotic spots & 1 \\
\hline & $\begin{array}{l}\text { Larger number and size } \\
\text { of necrotic spots }\end{array}$ & 2 \\
\hline & $\begin{array}{l}\text { Brown spots forming } \\
\text { coslescing lesioss of } \\
\text { intermediate size }\end{array}$ & 3 \\
\hline & $\begin{array}{l}\text { Large uniform bronn } \\
\text { lesions }\end{array}$ & 4 \\
\hline & $\begin{array}{l}\text { Very large brown lesions, } \\
\text { often expanding outside } \\
\text { the area corered by the } \\
\text { inoculum droplet. }\end{array}$ & 5 \\
\hline
\end{tabular}

Fig. 1: Leaf discs scored at 6 days after inoculation at $25^{\circ} \mathrm{C}$ for infection using a five point hedonic scale.

\section{Statistical analysis}

Initial analysis of the effect of storage medium on the Phytophthora isolates showed homogeneity of response and effects were species-specific. Data from five isolates of each species were then pooled for further analyses. Analysis of variance was used to assess the effect of storage medium on virulence and aggressiveness of the Phytophthora species using GenStat 11.1 (2008). The differences in the means were compared at $\alpha<0.05$ using Duncan multiple range test. Data on aggressiveness was arcsine transformed (Sin ${ }^{-1} \sqrt{X}$, where $\mathrm{X}=$ aggressiveness value) before analysis.

\section{Results}

The Phytophthora cultures from SDW and SSS media were still viable and grew actively on freshly prepared V8JA after 60 months (5 years) of storage (Table 1). Survival of cultures in these two storage media was similar for both species of Phytophthora. The next most effective medium for long-term storage was the empty (unfilled) tube where $P$. megakarya cultures remained viable for more than one year (15 months). Correspondingly, $P$. palmivora cultures were viable in the glass tube for a shorter period of 6 mnths. Isolates on OMA slant kept at $4{ }^{\circ} \mathrm{C}$ as routinely practiced in our laboratory were viable for 3 - 6 months. 
Other less effective media for the long term storage of Phytophthora were V8J broth and USS (Table 1).

TABLE 1

Viability of Phytophthora species in six different storage media at $26^{\circ} \mathrm{C}\left( \pm 2^{\circ} \mathrm{C}\right)$ for 60 months.

\begin{tabular}{|c|c|c|c|c|c|c|c|c|c|c|}
\hline \multirow{2}{*}{ Medium $^{1}$} & \multicolumn{10}{|c|}{ Assessment period (months) } \\
\hline & 3 & 6 & 9 & 12 & 15 & 18 & 24 & 36 & 48 & 60 \\
\hline SDW (Pp) & + & + & + & + & + & + & + & + & + & + \\
\hline SDW (Pm) & + & + & + & + & + & + & + & + & + & + \\
\hline $\mathrm{SSS}(\mathrm{Pp})$ & + & + & + & + & + & + & + & + & + & + \\
\hline SSS (Pm) & + & + & + & + & + & + & + & + & + & + \\
\hline USS (Pp) & + & + & + & - & - & - & - & - & - & - \\
\hline USS (Pm) & + & + & - & - & - & - & - & - & - & - \\
\hline V8J broth (Pp) & + & + & - & - & - & - & - & - & - & - \\
\hline V8J broth $(\mathrm{Pm})$ & + & + & - & - & - & - & - & - & - & - \\
\hline OMA slant (Pm)@4 ${ }^{\circ} \mathrm{C}$ & + & + & - & - & - & - & - & - & - & - \\
\hline OMA slant (Pp)@ $4^{\circ} \mathrm{C}$ & + & - & - & - & - & - & - & - & - & - \\
\hline Empty tube $(\mathrm{Pp})$ & + & + & - & - & - & - & - & - & - & - \\
\hline Empty tube (Pm) & + & + & + & + & + & - & - & - & - & - \\
\hline
\end{tabular}

Fungi (P. megakarya, $\mathrm{Pm}$ and P. palmivora, $\mathrm{Pp})$ grown on OMA $=$ oats meal agar, V8J = vegetable 8 juice. SSS $=$ sterilised soil suspension; USS = unsterilised soil suspension; SDW = sterile distilled water and empty tube containing mycelial plugs only. $+=$ present or $-=$ absent of colony growth.

The number of viable cultures detected using the Tetrazolium chloride test (TTC) was more than the agar plate test (Table 2). There were instances where mycelial plugs were found viable in the TTC but the plugs failed to grow on V8JA plate. This was more so among the Phytophthora megakarya isolates. The main survival structure of the Phytophthora species during storage was the thin- and thick-walled chlamydospores (Fig. 2). Thin- and thickwalled chlamydospores were defined as spherical spores having wall thickness less than $1 \mu \mathrm{m}$ and greater than $1.4 \mu \mathrm{m}$ (based on average value of 5 readings) respectively. On agar medium, the thin-walled chlamydospores germinated and produced new colonies readily than the thick-walled ones. 
TABLE 2

Influence of storage medium on survival, virulence (pod necrosis) and aggressiveness (vigour of growth) of Phytophthora species stored for 60 months (5 years).

\begin{tabular}{|c|c|c|c|c|c|c|}
\hline \multirow{2}{*}{ Medium $^{1}$} & \multicolumn{2}{|c|}{ Viability Test } & \multirow{2}{*}{$\begin{array}{l}\text { Pod necrosis } \\
\qquad\left(\mathrm{cm}^{2}\right)\end{array}$} & \multirow{2}{*}{ Aggressive ness } & \multirow{2}{*}{$\begin{array}{l}\text { Leaf } \\
\text { symptom } \\
\text { rating }\end{array}$} & \multirow{2}{*}{$\begin{array}{l}\text { Zoospores } \\
\left(\begin{array}{ll}x & \left.10^{4}\right) / \mathrm{ml} \\
\text { suspension }\end{array}\right.\end{array}$} \\
\hline & Tetrazolium & $\begin{array}{l}\text { Agar } \\
\text { Plate }\end{array}$ & & & & \\
\hline SDW (Pm) & + & + & $4.1 \mathrm{bc}$ & $0.7 \mathrm{a}$ & $0.4 b$ & 188 \\
\hline SDW (Pp) & + & + & $4.5 b$ & $0.5 b$ & $0.5 b$ & 213 \\
\hline $\mathrm{SSS}(\mathrm{Pm})$ & + & - & $5.4 \mathrm{a}$ & $0.7 \mathrm{a}$ & $0.4 b$ & 113 \\
\hline $\mathrm{SSS}(\mathrm{Pp})$ & + & + & $5.5 \mathrm{a}$ & $0.4 \mathrm{~b}$ & $3.1 \mathrm{a}$ & 513 \\
\hline \multicolumn{7}{|c|}{$\begin{array}{l}\text { Pre-storage } \\
\text { (initial } \\
\text { values) }\end{array}$} \\
\hline $\mathrm{Pm}$ & + & + & 8.1 & NA & 3.2 & 151 \\
\hline $\mathrm{Pp}$ & + & + & 7.7 & NA & 2.5 & 375 \\
\hline
\end{tabular}

Fungi (P. megakarya, $\mathrm{Pm}$ and $P$. palmivora, $\mathrm{Pp}$ ) stored in $\mathrm{SDW}=$ sterile distilled water and $\mathrm{SSS}=$ sterilised soil suspension. $+=$ present, $-=$ absent. Aggressiveness values less than $1=$ loss of aggressiveness; value above $1=$ increase in aggressiveness. Leaf symptom rating (0: Absence of symptoms, 1: initiation of small necrotic spots, 2: large number of small necrotic spots, 3: coalescence of brown-necrotic spots, 4: large, brown-lesions and 5: large, uniform, brown-lesions; often expanding).

There was significant effect of the storage medium on virulence and vigour of growth (aggressiveness) of the Phytophthora cultures. Virulence, measured in terms of necrosis sizes on cacao pod, was lower after 5 years of storage (Table 2). Among the treatments, however, cultures from SSS storage medium produced significantly $(\mathrm{P}<$ 0.05 ) higher necrosis on cacao pod than the SDW-stored cultures (Table 2). Also, there was reduction in the Phytophthora species vigour of growth after 5 years. The P. megakarya isolates however maintained higher $(\mathrm{P}<0.05)$ pathogenicity/vigour of growth than the $P$. palmivora (Table 2). All the stored cultures were capable of initiating lesions on cacao leaves. Curiously, the P. palmivora cultures from SSS storage produced larger, brown, coalescing, necrotic spots compared to the small, non-coalescing necrotic spots produced prior to storage. Generally, SDW and SSS media did not affect zoospores production of the cultures relative to the control. Overall growth of the Phytophthora species was consistent with the original descriptions in terms of colony, mycelial and sporangial characteristics (Fig. 3). 


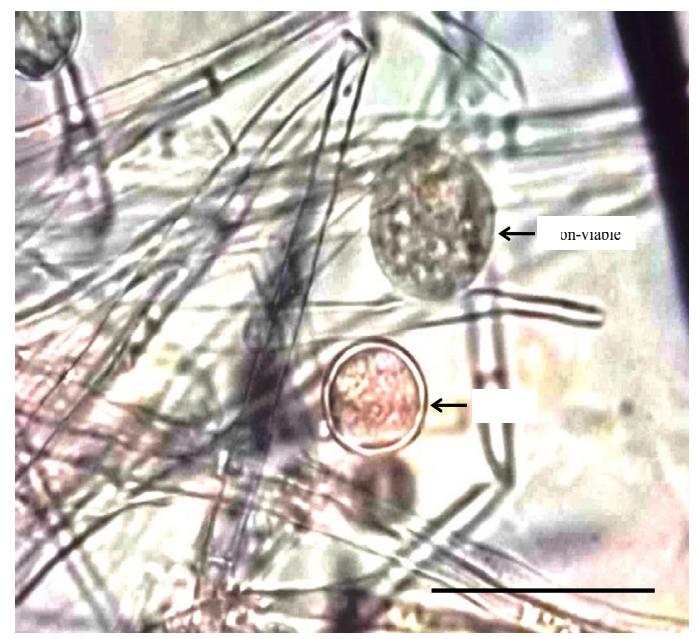

Fig. 2: Triphenyl Tetrazolium Chloride (TTC) staining of a 5-year-old Phytophthora culture. Note the pink (viable chlamydospore) and black (non-viable chlamydospore) colourations of the chlamydospores.
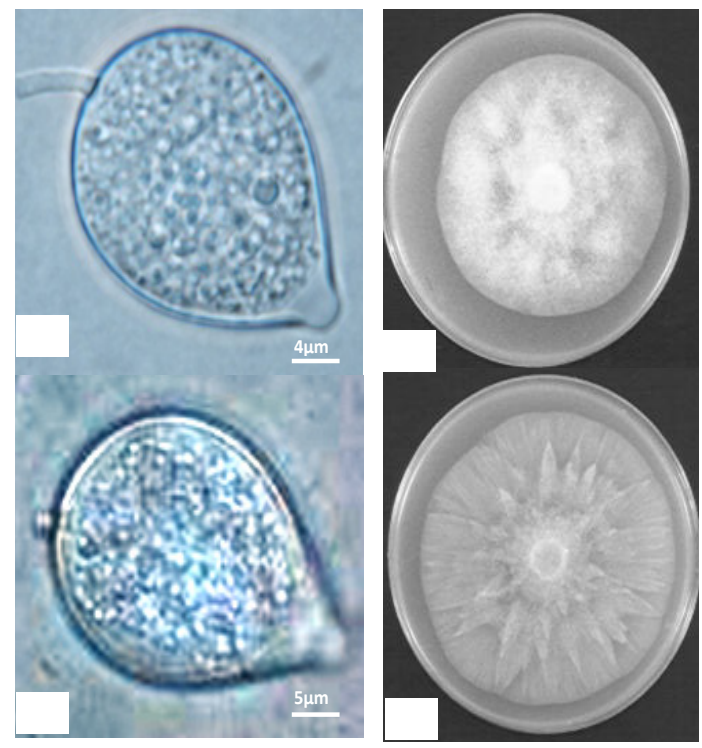

Fig. 3: Sporangial and cultural characteristics of Phytophthora megakarya (A= showing longer pedicle with $\mathrm{B}=$ cottony mycelial growth) and Phytophthora palmivora $(\mathrm{C}=$ shorter pedicles, $\mathrm{D}=$ stellate mycelial growth) after 60 months of storage.

\section{Discussion}

Phytophthora pod rot disease of cacao has remained one of the major constraints of cacao production for the chocolate industry worldwide and this is due to poor understanding of the molecular and biology of host-pathogen interaction. The extension of shelf-life of the causal agents (Phytophthora species) for research purposes has always been problematic. In this study however cultures of Phytophthora species, P palmivora and Phytophthora megakarya, were preserved successfully in SDW for 60 months (5 years). Sterile water medium has been used widely to store fungal cultures either at room temperature or at lower temperatures between $4^{\circ} \mathrm{C}$ and $5^{\circ} \mathrm{C}$ (Marx \& Daniel, 1976; Hartung De Capriles et al., 1989; Borba Cde et al., 1992; Burdsall Jr and Dorworth, 1994; Ko, 2003; Borman et al., 2006; Elliot 2005; Sutton et al. 2007, Roy et al., 2014; Cui et al., 2018). Most of the studies have confirmed that keeping the cultures at room temperature is more appropriate for long term storage than lower temperature. Ko (2003) reported 23 years viability of Phytophthora species kept in SDW at room temperature. Later, Sutton (2007) reported 6-year storage of some cultures of Phytophthora species in SDW at room temperature. These findings agree with our results and choice of room temperature for the long term preservation of P. palmivora and P. megakarya cultures.

Seasonal fluctuations in room temperature and high room temperature can be detrimental to Phytophthora isolates in storage. Puig et al., (2018) observed that cultures of $P$. palmivora and P. megakarya lost their viability after 3 days at temperatures of $36^{\circ} \mathrm{C}$ and $32^{\circ} \mathrm{C}$ respectively. In the present study, the ambient room temperature during the long term storage was $26^{\circ} \mathrm{C}\left( \pm 2^{\circ} \mathrm{C}\right)$. Based on these 
observations, temperatures recommended for long term storage of $P$. palmivora and $P$. megakarya in SDW should not exceed $28^{\circ} \mathrm{C}$.

In our laboratory, Phytophthora cultures on agar slants are kept at lower temperature $\left(4^{\circ} \mathrm{C}\right)$ under mineral oil. However, the shelf life was short and they did not store well. Another drawback to this method is the additional cost of electricity involved in maintaining low temperature during storage. Currently, the agar slant cultures stored under mineral oil has been replaced with water storage at room temperature. Also, the cultures of Phytophthora species were preserved in empty tubes for long term storage. Although, the vegetative growth of the cultures was preserved relative to the original ones, the $P$. palmivora isolates survived for 6 months. On the other hand, viability of $P$. megakarya isolates was extended for up to 15 months. The result is similar to Ward and Griffin (1981) who found out that $P$. megakarya survived longer for about 18 months while P. palmivora survived for 10 months on a fiberglass matrix.

Sterile water medium is an easy and cheaper way of preserving Phytophthora and other oomycete cultures for a longer period (Sutton et al. 2007, Roy et al., 2014; Cui et al., 2018). In this study, we modified the sterile water by replacing it with sterile soil suspension (SSS). The influence of the SSS medium on viability, growth characteristics and virulence of Phytophthora cultures were similar to the SDW. There were no significant changes in the morphological characteristics of the cultures before and after 5 year of storage, indicating that the medium (SSS or SDW) did not affect morphological and mycelium growth of the Phytophthoras. This is desirable for laboratories maintaining large collections of Phytophthora isolates to support on-going research. However, in some instances, there were reduction in virulence and vigour of growth of the Phytophthora cultures after storage in SSS or SDW as compared with the original growth. Although the exact cause of this reduction is not known, it may be conjectured that the long period of storage of the cultures or lack of a host stimulus for growth may be responsible for this observation. The only means of restoring aggressiveness and vigour of fungal growth is by successive re-inoculation of original host plant tissue. Indeed, Sobkowiak et al., (2004) reported significant increase in aggressiveness of Phytophthora infestans after many times reinoculation of potato tuber slice as compared with a one-time re-inoculation of host tissue. It is therefore necessary to determine the exact number of re-inoculations of cacao pods required for P. palmivora and P. megakarya isolates to sustain their pathogenicity in future studies.

Many fungi survive unfavourable environmental conditions by producing chlamydospores. In this study, the main survival unit of the Phytophthora species during storage was production of spherical chlamydospores. Ko, (2013) reported a similar mechanism of maintaining Phytophthora species during 23 years of storage in SDW at room temperature $\left(24^{\circ} \mathrm{C}\right.$ to $\left.25^{\circ} \mathrm{C}\right)$. In our study, both thick- $(>1.4 \mu \mathrm{m})$ and thin-walled $(<1 \mu \mathrm{m})$ chlamydospores were formed by the Phytophthoras in SDW and SSS but the thinwalled chlamydospores germinated readily on fresh V8JA media. Moreover, sporangia formation by the de novo mycelium produced by the germinating chlamydospores released zoospores akin to those recorded prior to storage.

There was one other interesting observation. The unsterilised soil suspension (USS) was a poor medium to maintain 
pathogenicity of the two Phytophthora species (Table 1). The USS maintained viability for 6-9 months. On the other hand, SSS maintained the viability of the pathogens for up to 60 months (5 years). It is well known that fungi growing in soil or culture produce 'staling metabolite' which is responsible for inhibiting growth after a certain period of incubation (Kendrick 2000; Grifin 1981). After sterilization, the volatile 'staling metabolites' which are responsible for growth retardation are inactivated hence the differences observed in the viability of the cultures.

\section{Conclusion}

The study has shown that sterile distilled water (SDW) and sterilised soil suspension (SSS) are suitable for long-term storage of the cultures of P. palmivora and P. megakarya. The morphological characteristics of the mycelium and sporangial formation as well as discharge of zoospores from the zoosporangium were not seriously affected during the 5-year storage period. The mycelium of the surviving Phytophthoras formed chlamydospores which were either thin-walled $(<1 \mu \mathrm{m})$ or thick walled $(>1.4 \mu \mathrm{m})$. The thin-walled chlamydospore germinated readily on V8JA. However, long term storage affected the vigour of the pathogenicity of the fungal cultures which required re-inoculation onto host tissue (cacao pods) to restore virulence to an appreciable level. It is not certain from this paper how many re-inoculations onto host tissue are required to sustain the viability of the fungus during prolonged storage of 5 years. This could form the basis for future investigations to spur researchers on to find a lasting solution to the storage of Phytophthora cultures for research purposes.

\section{Acknowledgement}

We are grateful to the staff of the mycology laboratory of Cocoa Research Institute of Ghana (CRIG) for the technical assistance. This paper (CRIG/04/2021/003) is published courtesy the Executive Director of CRIG, Akim Tafo.

\section{References}

AnsARI, M. A. \& ButT, T. M. (2011) Effects of successive sub culturing on stability, virulence, conidial yield, germination and shelf-life of entomopathogenic fungi. $J \mathrm{Appl}$ Microbiol. 110 (6), 1460 - 1469. doi:10.1111/ j.1365-2672.2011.04994.x

Bailey, B. A., Ali, S. S., Akrofi, A. Y. \& Meinhardt, L. W. (2016). Phytophthora megakarya, a causal agent of black pod rot in Africa. In: B. A. Bailey and L. W. Meinhardt (Eds), Cacao Diseases: A History of Old Enemies and New Encounters. pp 267-303 Springer International Publishing, Switzerland. ISBN 978-3-319- 24787-8

Borbacde, M., Da Silva, A. M. \& De Oliveira, P. C. (1992). Long-time survival and morphological stability of preserved Sporothrix schenckii strains. Mycoses 35 (7 - 8), $185-188$.

Borman, A. M., Szekely, A., Campbell, C. K. \& Johnson, E. M. (2006). Evaluation of the viability of pathogenic filamentous fungi after prolonged storage in sterile water and review of recent published studies on storage methods. Mycopathologia 161 (6), 361 - 368.

Burdsall, J. R., H. H. \& Dorworth, E. B. (1994). Preserving cultures of wood-decaying Basidiomycotina using sterile distilled water in cryovials. Mycologia 86 (2), $275-280$.

Cui, H., Ren, X., Yun, L., Hou, Q., Feng, F. \& Liu, H. (2018). Simple and inexpensive longterm preservation methods for Phytophthora 
infestans. Journal of Microbiological Methods 152 (2018) 80 - 85.

DAKwA, J. T. (1988). A serious outbreak of the black pod disease in a marginal area of Ghana. Proceedings of the Tenth International Cocoa Research Conference, 1987, Santa Domingo: Dominican Republic. pp. 447 - 451.

Elliotr, M. L. (2005). Survival, growth and pathogenicity of Gaeumannomyces graminis var. graminis with different methods of longterm storage, Mycologia 97 (4), 901- 907, DOI: $10.1080 / 15572536.2006 .11832781$.

Ferguson, A. \& JefFers, S. (1999). Detecting multiple species of Phytophthora in c o n t a i n e r mixes from ornamental crop nurseries. Plant Disease 83, 1129 - 36.

Granke, L. L., Quesada-Ocampo, L. M. \& Hausbeck, M. K. (2012). Differences in virulence of Phytophthora capsici isolates from a worldwide collection on host fruits. Eur J Plant Pathol 132, 281 - 296. https://doi. org/10.1007/s10658-011-9873-4.

Griffin, D. H. (1981). Fungal Physiology. John Wiley and Sons, New York. 383pp. ISBN-041705748-7.

Hartung De Capriles, C., Mata, S. \& Middelveen, M., (1989). Preservation of fungi in water (Castellani): 20 years. Mycopathologia 106 (2), $73-79$.

Johnson, G. C. \& Martin, A. K. (1992). Survival of wood inhabiting fungi stored for 10 years in water and under oil. Can J Microbiol 38, 861 -864 .

Kellam, M. \& Zentmyer, G. (1986). Morphological, physiological, ecological, and pathological comparisons of Phytophthora species isolated from Theobroma cacao, Phytopathology 76, $159-164$.

Kendrick, B. (2000). The fifth Kingdom. $3^{\text {rd }}$ Ed. Focus Publishing R Pullins Co. Massachusetts USA. Pp 373 ISBN 1-58510-022-6.
Ko, W. H. (2003). Long-term storage and survival structure of three species of Phytophthora in water. J. Gen. Plant Pathol. 69 (3), 186 - 188.

Losch, A., Hutwimmer, S. \& Strasser, H. (2010). Carbon utilization pattern as a potential quality control criterion for virulence of Beauveria brongniartii. J Invertebr Pathol 104, $58-65$.

Marx, D. H. \& Daniel, W. J. (1976). Maintaining cultures of ectomycorrhizal and plant pathogenic fungi in sterile water cold storage. Can. J. Microbiol. 22 (3), 338 - 341.

Nyadanu D., Assuah M.K., Adomako B., Asiama Y. O., ОРокU I.Y. \& ADU-АмРомAн Y. (2009). Efficacy of screening methods used in breeding for black pod disease resistance varieties in cocoa. Afri Crp Sc Jnl, 17 (4) 175 $-186$.

Nyasse', S., Cilas, C., He' Rail, C. \& Blaha, G. (1995). Leaf inoculation as an early screening test for cocoa (Theobroma cacao L.) resistance to Phytophthora black pod disease. Crop Protection 14, 657 - 663.

Puig A. S., Ali S., Strem M., Sicher R., Gutierrez O. A. \& Bailey B. A. (2018). The differential influence of temperature on Phytophthora megakarya and Phytophthora palmivora pod lesion expansion, mycelia growth, gene expression, and metabolite profiles. Physio Molecular Plant Patho 102, 95 - 112.

Roy, C. B., Srinivas, P. \& JACOB, C. K. (2014). Relative efficacy of long-term storage methods on survival and virulence of Corynespora cassiicola and Phytophthora meadii pathogenic on rubber (Hevea brasiliensis). Rubber Sci. 27 (2), 202 - 214.

Ryan, M. J., Smith, D. \& Jeffries, P. (2000). A decision-based key to determine the most appropriate protocol for the preservation of fungi. World J. Microbiol. Biotechnol, 16, 183 -186 .

Sobkowiak, S., ZarzycKa, H., \& ŚliwKa, J., (2012). The influence of long-term storage in liquid 
nitrogen on survival and pathogenicity of Phytophthora infestans isolates. J. Plant Prot. Res. 52 (4), 479 - 485 doi: 10.2478/v10045012-0077-5.

Surujdeo-Maharaj, S., Sreenivasan, T. N. Motilal, L. A. \& Umaharan, P. (2016). Black pod and other Phytophthora induced diseases of cacao: History, Biology, and Control. In: B. A. Bailey and L. W. Meinhardt (Eds), Cacao Diseases: A History of Old Enemies and New Encounters. pp 213 - 266 Springer International Publishing, Switzerland.

Sutton, W., Reeser, P. \& Hansen E. (2007). Longterm storage of Phytophthora cultures in water. Proceedings of the Fourth Meeting of IUFRO Working Party S07.02.09, Phytophthoras in Forests and Natural Ecosystems, August 26 31, 2007, Monterey, California, USA.
Świszczewska, J., Osińska, M., \& Piotrowski, W. (1971). Pathogenicity of Phytophthora infestans Mont. de Bary races in dependence on the biotype, substrate and season. Biul. Inst. Ziemn. 8 (1), $21-27$.

WARD, M., \& GRIFFIN, M. (1981). Soil phase of cocoa Phytophthora. In: P. H. Gregory and A. C. Maddison (Eds.), Epidemiology of Phytophthora on cocoa in Nigeria (Vol. 25, pp. 50 - 61). Kew: Commonwealth Mycological Institute.

Windels, C. E., Burnes, P. M. \& Kommedahl, T. (1993). Fusarium species stored on silica gel and soil for ten years. Mycologia 85, $21-23$.

Received 20 Oct 20; revised 25 Jun 21. 